\title{
Yes/No Interrogative Intonation of Satipo Ashaninka (Kampa Arawak) of Peru
}

\author{
Elena Mihas ${ }^{1}$, Olga Maxwell ${ }^{2}$ \\ University of Wisconsin-Milwaukee, USA \\ ${ }^{2}$ School of Languages and Linguistics, University of Melbourne, Australia \\ elmihas@uwm.edu, omaxwell@unimelb.edu.au
}

\begin{abstract}
The paper presents a pioneering analysis of the yes/no interrogative intonation of Satipo Ashaninka, a highly synthetic Kampa Arawak language spoken by approximately 10, 000 people in the Satipo Province of Peru. The study demonstrates the diversity of the Satipo Ashaninka interrogative intonation types, most of which are combined with the language's morphosyntactic resources. Yes/no interrogative intonation types comprise low and high right edge boundary tones. The results confirm the findings of other studies across synthetic indigenous languages by providing evidence that yes/no interrogative intonation does not necessarily have a rising pitch contour.
\end{abstract}

Index Terms: Satipo Ashaninka, Kampa Arawak, interrogative intonation, yes/no questions

\section{Introduction}

The study responds to the concern of contemporary prosodic typology with the intonational patterns of interrogatives across languages [1]. Interrogative prosody is commonly deployed in yes/no questions. Discourse studies offer evidence that rising intonation is not strongly indicative of a yes/no question. Such questions are not necessarily marked with rising intonation, and rising intonation does not always mark an utterance as a yes/no question $[2,3]$. The typology of yes/no interrogative intonation proposed for the indigenous languages of Africa [1] suggests that the yes/no interrogative intonation is cued by 'highpitched' and 'non-high pitched prosodic markers'. Among the common 'high-pitched' markers are pitch register expansion, reduction of the final lowering, and final high tone; the final HL tone and High-falling intonation illustrate the "non-high-pitched prosodic markers'.

Moreover, there is a dearth of research on the prosody of yes/no interrogatives in polysynthetic indigenous languages. These languages have long morphologically complex words, and are known for the interaction of their morphology with the marking of pitch prominence [4] and for various intonation contours of yes/no interrogatives $[5,6,7,8,9,10]$. The present study is highly relevant to prosodic typology as it describes the yes/no interrogative intonation in a highly synthetic Amazonian language. This work presents a first of its kind instrumental analysis of the interrogative intonation of a Kampa Arawak language, shedding light on the subject of significant interest to the typological research on intonation in this language family.

Satipo Ashaninka is a Kampa Arawak language spoken by approximately 10, 000 people in the Chanchamayo and Satipo Provinces of Peru [11]. All speakers are bilingual in the local language and Spanish. The proficiency level in the local language varies but the most fluent speakers are in their 40s and older. There are some published descriptions of the grammatical structure of Satipo Ashaninka, and a grammar is in preparation $[12,13]$. There is one publication on Ashaninka stress [14], but the language has never been a subject of extensive research on its prosody and intonational phonology. This paper is the first focused study of intonation of Ashaninka Kampa spoken by the speakers from the Chanchamayo and Satipo Provinces of Peru.

The study's broad goal is to identify the intonational patterns of Satipo Ashaninka yes/no interrogatives. The research analysis deals with the prosodic structure, the contours of declaratives and content questions, yes/no interrogative strategies, and the role of the final boundary tones in the production of the Satipo Ashaninka yes/no interrogative intonation.

\section{Declarative Intonation in Satipo Ashaninka}

\subsection{Prosodic structure}

The language is verb-initial, VS/VOA, but a focus constituent could be fronted to occupy the preverbal position. Topical information usually follows the verb. The basic prosodic unit is the prosodic word (PW), which is the domain of stress assignment. The prosodic word is isomorphic with a phonological word (prosodic units form phonological domains). The stress system shows weight sensitivity. The heavy syllables CVV, CVN, and CVVN generally attract stress. Overall, Satipo Ashaninka is a stress accent iambic language (with the weakstrong and right headed iamb). The primary metrical stress is associated with an increase in duration and fundamental frequency and intensity.

Two other units of prosodic structure include a phonological phrase (pp) and an intonational phrase (IP). Two grammatical words could form a phonological phrase if one of them is a mono- or disyllabic word. The left edge boundary tone usually carries strong pitch prominence. The demarcative function of the left edge boundary tone is also manifest in the genetically related and geographically adjacent Alto Perené (Kampa Arawak) in [15].

The phonological phrase (pp) is characterized by the final high tone (Hp). The pp is either isomorphic to the grammatical word, or it could contain a content word and another word, e.g., a noun, a verb, a conjunction, or an adverb. The Intonational Phrase (IP) consists of one or more phonological phrases. Depending on the type of an utterance, intonational phrases (IP) are associated with a particular pitch register. For example, commands and content questions are articulated at a higher level of the speaker's pitch range. Another characteristic is the presence or suspension of downtrend. In particular, declarative intonation is gradually downtrending (\$2.2), whereas in 
negative interrogatives, the downtrend is suspended (\$4.3.1). The final boundary tone is another distinct characteristic. The final boundary tone is $\mathrm{L} \%$ in declaratives and content questions, and queclaratives (which are assertions packaged as questions, [16]). The High boundary tone $(\mathrm{H} \%)$ is found in enumerated NPs, non-main clauses, and tags.

\subsection{Declaratives}

A declarative statement is characterized by gradual downtrend, with the first pitch prominence being the highest, and other peaks being less prominent. It has a final Low boundary tone. The final fall is close to the speaker's pitch range baseline. In Figure 1, the first peak associated with a high pitch accent is the highest $(292 \mathrm{~Hz})$, followed by two lowered peaks and a final drop to the speaker's pitch range low point $(102 \mathrm{~Hz})$ at the right boundary.

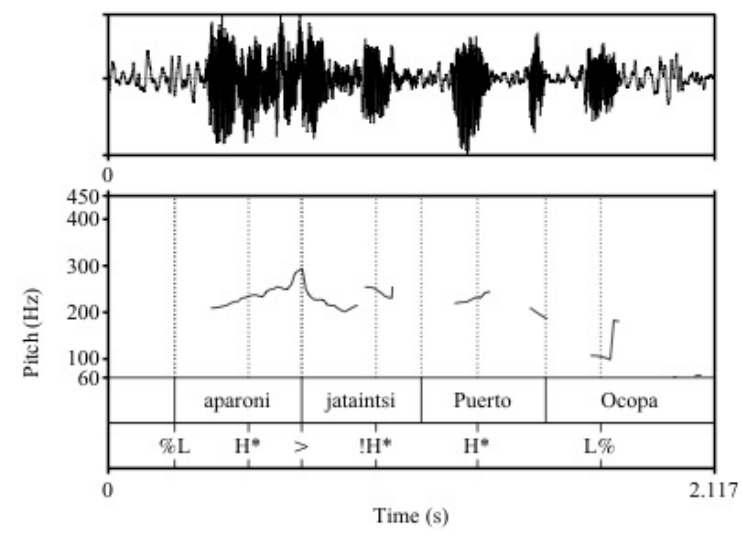

Figure 1: Intonation contour of the declarative, aparoni ja-taintsi Puerto Ocopa (one go-EP-STAT.3S PLACENAME) 'one (child) has gone to Puerto Ocopa'.

In narrative contexts and instances of continuation and enumeration, declarative intonation is characterized by high pitch at the right boundary $(\mathrm{H} \%)$, realized in the mid-level of the speaker's pitch range. In combination with the preceding high pitch accent(s), the intonational contour is often represented by sustained high pitch.

\subsection{Content interrogative}
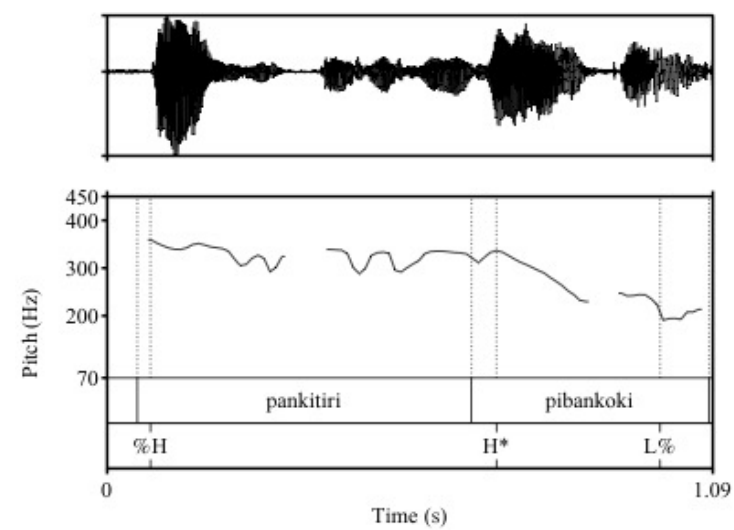

Figure 2: Intonation contour of the content question, pi-pankit-i-ri pi-banko-ki? (2S-plant-EP-REAL-NMZ 2POSS-house-LOC) 'What do you plant in your house (garden)?'
In the content interrogative question, interrogative words always occupy the clause-initial position. In casual speech, the interrogative words jaoka 'where, what, which, how much/many' and paita 'what' are frequently omitted. For example, the interrogative word paita 'what' is absent in Figure 2. Content questions have a falling contour. The contour is characterized by pitch expansion at the left boundary and a final fall to the speaker's pitch range baseline. The final tune $\left(\mathrm{H}^{*}\right.$ $\mathrm{L} \%$ ) has a greater magnitude of the fall compared to declaratives. The common left edge phenomena are the deletion of the initial syllables of the interrogative word (or its complete elision) and a fast tempo of the production of the initial syllables which are marked by an elevated pitch peak. The strongly elevated pitch prominence at the left edge of the IP is illustrated in Figure 2. The $\% \mathrm{H}$ tone measuring at $359 \mathrm{~Hz}$ is realized in the upper level of the speaker's pitch range.

\section{Methodology}

\subsection{Corpus and materials}

The research methods include a production of a documentary corpus of audio and video recordings of naturally occurring discourse, observation of speakers' communicative practices, and elicitation. The study is based on a combination of qualitative observations about Satipo Ashaninka prosody made over several years of fieldwork on the language as well a series of elicited recordings targeting particular properties of the prosodic system for both qualitative and quantitative study. The data come from the first author's multiple field trips to Peru, spanning the period of 7 months. During fieldwork, the 12-hour corpus of audio recordings of 16 speakers was collected (4 males and 12 women). The recordings consist of narratives, conversation, elicited word lists and sentences recorded from speakers designed to illustrate the features of word prosody, phrasal intonation patterns, and prosodic constituency. The recordings were made at a sampling rate of $44.1 \mathrm{kHz}$ onto a Marantz (PMD 661) solid state recorder. To collect the targeted data on yes/no interrogatives for this study, seven recordings of conversation were selected, with the running time of over three hours.

The illustrative examples in the figures are given in the official orthography of the Ashaninka language, where $<b>$ stands for the bilabial approximant $/ \mathrm{w} /,<j>$ for the glottal fricative $/ \mathrm{h} /$, and $<$ ts $>$ for the aspirated affricate $/ \mathrm{ts}^{\mathrm{h}} /$.

\subsection{Speakers}

The data providers are four female and one male speakers from the village of Impitato Cascada, Pichanaki District, Chanchamayo Province, Junín, Peru. All speakers are bilingual in Spanish and Satipo Ashaninka, and use the local language daily as a medium of communication. They are over 50 years old, and all except one have primary education. The gender imbalance in the selection of speakers is explained by the language and culture-specific interpersonal norms in that yes/no interrogative strategies are predominantly used by females.

\subsection{Framework and analysis}

The recordings were annotated in Praat [17]. The intonational analysis was performed following the Autosegmental-Metrical framework [18], and the F0 contours were annotated using tonetarget analysis. Auditory and visual analyses were performed to identify pitch movements corresponding to pitch accents, 
phrase accents and boundary tones. High pitch accent $\left(\mathrm{H}^{*}\right)$ was the most commonly observed accent in the data. High pitch accents produced with a lowered peak relative to the preceding high peak were labelled as $! \mathrm{H}^{*}$. Four boundary tones marking the edges of the IP were identified for the present dataset: IPinitial high $(\% \mathrm{H})$ and low $(\% \mathrm{~L})$ tones, and IP-final high $(\mathrm{H} \%)$ and low tones $(\mathrm{L} \%)$.

\section{Results}

\subsection{Prosody of Yes/No Questions}

There is a variety of language-specific strategies of asking yes/no questions. The strategies are characterized by the particular intonation contour, pitch register and final boundary tones, summarized in Table 1.

Table 1. Strategies of asking yes/no questions

\begin{tabular}{|l|l|l|}
\hline Strategy & $\begin{array}{l}\text { Contour } \\
\text { configuration and } \\
\text { pitch range }\end{array}$ & $\begin{array}{l}\text { IP-final } \\
\text { boundary tone }\end{array}$ \\
\hline Queclarative & $\begin{array}{l}\text { Falling, mid-range } \\
\text { of speaker's pitch } \\
\text { range }\end{array}$ & Low \\
\hline $\begin{array}{l}\text { Negative } \\
\text { interrogative }\end{array}$ & $\begin{array}{l}\text { Level, sustained high } \\
\text { pitch in the middle or } \\
\text { upper part of } \\
\text { speaker's pitch range }\end{array}$ & High \\
\hline Tags & $\begin{array}{l}\text { High rising of the } \\
\text { last high tone of the } \\
\text { tag word }\end{array}$ & High \\
\hline
\end{tabular}

\subsection{Low boundary tones}

Intonation contours and low boundary tones in queclaratives, which are yes/no questions disguised as assertions, are illustrated by Figures 3 and 4 .

\subsubsection{The queclarative strategy}

Queclaratives are the most common yes/no interrogative strategy. The syntax of queclaratives is indistinguishable from that of declaratives. There is no syntactic movement of the clausal constituents, with the basic constituent order remaining intact, VS/VO. As illustrated in Figure 3, the verb in the first IP is followed by a full noun phrase, [Verb + Locative NP].

The queclaratives have a final low tone and are represented by a falling contour $\left(\mathrm{H}^{*} \mathrm{~L} \%\right)$, as can be seen in Figures 3 and 4 . The majority of the collected tokens have a high F0 onset (Figure 4). However, in a smaller portion of the data, queclaratives exhibit a low F0 onset followed by a high pitch accent(s) and a low boundary tone at the right edge (Figure 3 ). The low onset queclaratives are very similar phonologically to the declaratives: both have a characteristic rising-falling contour. Preliminary analysis indicates no significant difference in the F0 height of the low boundary tone (L\%) between declaratives and queclaratives, but suggests a possible difference in the phonetic realization of F0 peaks associated with phrase-initial and/or phrase-final pitch accents, and potentially greater magnitude of the fall. Further analyses need to be performed to determine what gradient phonetic cues contribute to the distinction between declaratives and queclaratives.
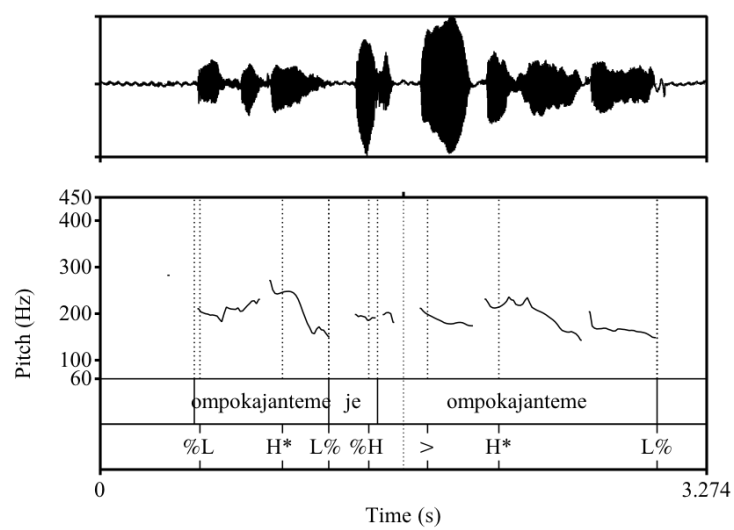

Figure 3: The contours of the queclarative, o-m-pok-ajant$e=m e$ (3NM.S-IRR-come-TERM.FOC-IRR $=$ CNT.F) 'is she supposed to come?' followed by the responsive declarative statement, je o-m-pok-ajant-e =me (yes 3NM.S-IRR-come-TERM.FOC$I R R=C N T . F)$ 'yes, she is supposed to come'.
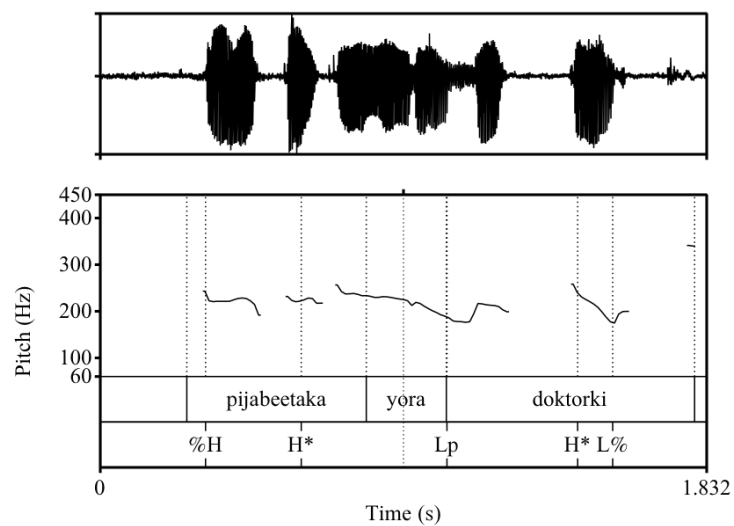

Figure 4: The contour of the queclarative, pi-ja-bee-t-ak-a yora doctor-ki (2S-go-FRUS-EP-PFV-REAL DEM.NOM doctor-LOC) 'did you go to that doctor?'

\subsection{High boundary tones}

High boundary tones are illustrated by the negative interrogatives and tags in Figures 5 and 6.

\subsubsection{Negative interrogative question strategy}

The negative interrogative is a 'marked' interrogative strategy in that it greatly increases the pressure on the recipient to concur with the first speaker [19]. Negative interrogatives are based on the negative interrogative construction [Neg. Particle + Verb], which could be followed by other clausal constituents. In Figure 5 , the negated verb is followed by the temporal adverb meeka 'already' and the noun pearentsi 'manioc beer'. The interrogative is produced in the higher part of the speaker's pitch range, with the $\mathrm{F} 0$ onset of $310 \mathrm{~Hz}$.

\subsubsection{Tag question strategy}

The tag question strategy is based on the syntactic template [Declarative $+\mathrm{Tag}]$. Both the affirmative and negative tags, ñakiro 'you have seen it?' and teario keario 'isn't it the case?', respectively, are articulated as independent higher level 
prosodic units (IP) after a pause. Both tags are characterized by the sharply rising tone on the last syllable. Figure 6 illustrates the negative tag intonation. In this question, the speaker uses self-repair when he articulates the first few syllables of the verb $o b$ place' and abandons it in favor of another verb. The tag teario forms its own IP. As shown in the figure, the high pitch peak on the prominent syllable $(235 \mathrm{~Hz})$ is followed by a steep rise at the right boundary $(394 \mathrm{~Hz})$.

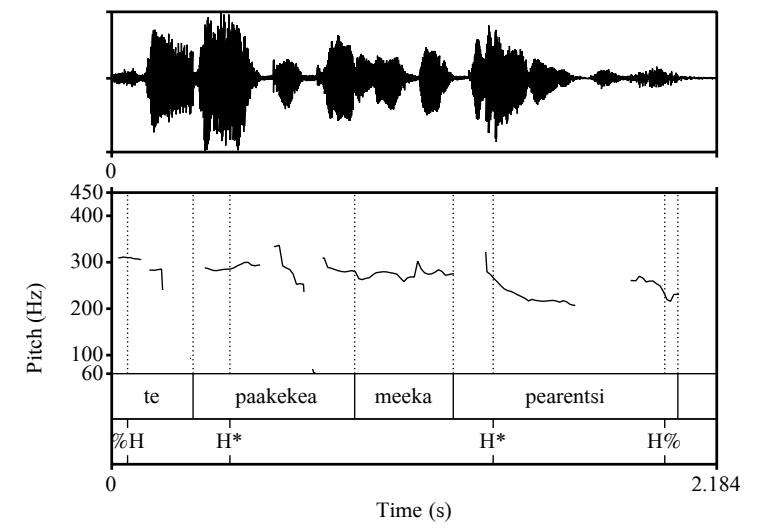

Figure 5: The contour of the negative interrogative, te $p$ - $a$ ak-e=kea meeka pearentsi (NEG.REAL 2s-take-PFV$I R R=A S S E R T$ already manioc.beer) 'didn't you get manioc beer already?'
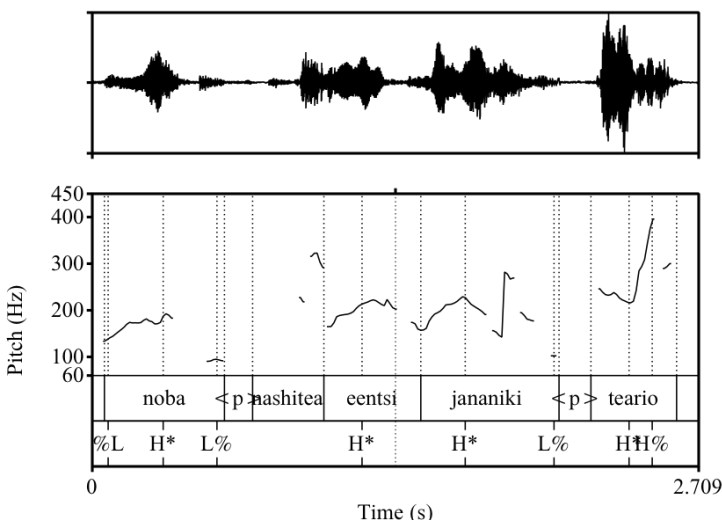

Figure 6: The contour of the negative tag teario in no-b-a n-ashi-t-ea eentsi jananiki teario (1SG.S-place-EP 1SG.Sown-EP-IRR child little.child NEG.TAG) 'I will lay- will father a little child, isn't it the case?'

\section{Discussion}

The study's results are highly relevant to prosodic typology as they provide insights into the typology of interrogative intonation in a highly synthetic small indigenous language. The results are especially valuable considering the overall dearth of research on the intonation and prosody of polysynthetic languages and especially the indigenous South American languages.

A significant finding of the study concerns the interplay of the intonational phonology and morphosyntax in the realization of the yes/no interrogative strategies. While the morphosyntax of queclaratives is indistinguishable from that of a declarative clause, negated interrogatives and tags rely on the specific grammatical constructions, used in combination with the particular marking of prosodic boundaries.

Another important result involves the distinct right edge phenomena of the yes/no interrogative strategies, namely, the final boundary tones. Depending on the strategy, the final boundary tone is either low (in queclaratives, §4.2), or high (in negated interrogatives and tags, §4.3).

An outcome of special typological interest deals with the low realization of the final boundary tone in queclaratives. A similar drop to the speaker's pitch range baseline also happens in Satipo Ashaninka content questions (§2.3). This finding is aligned with the results of interrogative intonation studies in some indigenous languages of North America which appear to indicate a preference for either high or low boundary tones of the content and yes/no interrogatives, corresponding to rising and falling intonational contours. For example, in Chickasaw both wh-questions and yes/no questions have a falling contour [6], and in Koasati both have rising contours [7].

Future work will focus on testing for the possibility of matching yes/no intonation contours in the geographically adjacent Kampa Arawak languages. The future research will also investigate a possible influence of the yes/no intonational patterns of Spanish on the Satipo Ashaninka speakers' realization of the yes/no interrogative intonation in native speech.

\section{Conclusions}

The study has demonstrated the variety of interrogative intonation types in Satipo Ashaninka, a highly synthetic Amazonian Kampa Arawak language of Peru. The particular features of the Satipo Ashaninka yes/no interrogative contours are realized in combination with the language's morphosyntax. The most common yes/no interrogative strategy is produced on the basis of queclaratives, which are assertions disguised as questions. Queclaratives exhibit a falling final boundary tone. Other yes/no strategies, such as negative interrogatives and tags have a rising right edge boundary tone. The study provides evidence that yes/no interrogative intonation does not have to exhibit a rising intonation contour thus confirming the diversity of yes/no interrogative tunes types across polysynthetic indigenous languages.

\section{Acknowledgements}

We would like to thank the speakers of Satipo Ashaninka (Kampa Arawak) for their valuable contribution to this study. The fieldwork was funded by the James Cook University Faculty Grants $(2013,2015)$ and by the Language and Culture Research Centre of James Cook University (2015-2016), for which we are grateful.

\section{Abbreviations}

1-first person; 2-second person; 3-third person; A-subject of transitive clause; ASSERT-assertive; CNT.F- counter-factual; DEM-demonstrative; EP-epenthetic; FOC-focus; FRUSfrustrative; IRR-irrealis; LOC-locative; M-masculine; NEGnegative; NM-non-masculine; NOM-nominal; O-transitive object; PFV-perfective; PL-plural; REAL-realis; S-subject of intransitive clause; STAT-stative; TERM-terminative. 


\section{References}

[1] A. Rialland, "Question prosody: an African perspective", in T. Riad, and C. Gussenhoven, Eds., Tones and tunes, Vol.1, Typological studies in word and sentence prosody. Berlin: Mouton, 2007, pp. 35-62.

[2] M. Selting, "Prosody in conversational questions". Journal of Pragmatics, vol. 17 (4), pp. 315-345, 1992.

[3] T. Stivers, N. J. Enfield, and S. C. Levinson, "Question-response sequences in conversation across ten languages". Journal of Pragmatics [Special issue] vol. 42 (10), pp. 2615-2860, 2010.

[4] K. Rice, "Accent in the native languages of North America". In H. van der Hulst, R. Goedemans, and E. van Zanten, Eds. A survey of word accentual patterns in the languages of the world. Berlin: Mouton de Gruyter, 2010, pp. 155-248.

[5] M. Milligan, Menominee prosodic structure. Madison: University of Wisconsin dissertation, 2005.

[6] M. Gordon, "Intonational phonology of Chickasaw". In Sun-Ah Jun, Ed. Prosodic typology: The phonology of intonation and phrasing. Oxford: Oxford University Press, 2005, pp. 301-330.

[7] M. Gordon, J. Martin, and L. Langley, "Prosodic structure and intonation in Koasati", in Proc. of ICPhS 2015, - the 18th International Congress of Phonetic Sciences, Glasgow, UK, Proceedings, 2015.

[8] J. Fletcher, "Intonation and prosody in Dalabon", in Sun-Ah Jun Ed. Prosodic typology II. Oxford: Oxford University Press, 2014, pp. 252-272.

[9] J. Fletcher, H. Stoakes, R. Singer, and D. Loakes, "Intonational correlates of subject and object realisation in Mawng (Australian)", in Proc. of Speech Prosody 2016, Boston, USA, 2016, pp.188-192.

[10] G. Schwiertz, Intonation \& prosodic structure in Beaver (Athabaskan). Cologne: Universität zu Köln dissertation, 2009.

[11] Ñ. R. Guillermo, Mesozonificación ecológica y económica para el desarrollo sostenible de la Provincia de Satipo. Caracterización social y antropológica. Iquitos: Instituto de Investigaciones de la Amazonía Peruana, 2010.

[12] E. Mihas, "Imperatives in Ashaninka Satipo (Kampa Arawak)", in A. Aikhenvald and R.W.M. Dixon, Eds. Commands: A crosslinguistic typology. Oxford: Oxford University Press, 2017, pp. 83-105.

[13] E. Mihas, A grammar of Satipo Ashaninka with comparative notes on other Northern Kampa Arawak languages of Peru. Lincoln: University of Nebraska Press, forthcoming.

[14] K. Pike, and W. Kindberg, "A problem in multiple stresses", Word, vol. 12, pp. 415-428, 1956.

[15] E. Mihas, Conversational structures of Alto Perené (Arawak). Amsterdam: John Benjamins, 2017.

[16] J. M. Sadock, "Queclaratives", Papers from the Seventh Regional Meeting of the Chicago Linguistic Society, April 16-18, vol.7, pp. 223-232, 1971.

[17] P. Boersma, and D. Weenink, Praat: Doing phonetics by computer (Version 6.02.24), 1992-2017. Available from http://www.praat.org/.

[18] D. R. Ladd, Intonational phonology. Cambridge: Cambridge University Press, 2008.

[19] J. Heritage, and G. Raymond, "The terms of agreement: Indexing epistemic authority and subordination in talk-in-interaction", Social Psychology Quarterly, vol. 68, pp. 15-38, 2005. 